\title{
“KETIKA MEMORI PENDERITAAN DIPERJUMPAKAN" Sebuah Kajian Dialogis Kitab Daniel dan Sejarah Penjajahan Jepang di Indonesia dalam Perspektif Poskolonial
}

\section{Yan Okhtavianus Kalampung}

\author{
Dosen Perjanjian Lama \\ Institut Agama Kristen Negeri Manado \\ Email:vian.pemimpi@gmail.com
}

\begin{abstract}
The experience of being a colony is certainly a wound that is difficult to forget by those who have experienced it. Especially if the experience is passed down from generation to generation. This paper will then try to reveal some of that through the postcolonial approach by exploring the experience of the Jews as a colonial nation described by the "Little Horn" in Daniel 8. The book of Daniel saves Daniel's experience as a Babylonian colony but is also intended for Jewish readers while in colonialism it was then dialogue with the experience of the Indonesian people who had been a Japanese colony. The dialogue of these two contexts will show that the memory of colonialism can be interpreted as a memory of suffering.
\end{abstract}

Keywoords : Old Testament, Daniel, Postcolonial, Antiochus IV Epiphanes, Japanese Colonialism, Jews, Indonesia.

\begin{abstract}
Abstrak
Pengalaman menjadi bangsa jajahan tentu menjadi sebuah luka yang sulit untuk dilupakan oleh yang pernah mengalaminya. Apalagi kalau pengalaman itu diwariskan secara turuntemurun dari generasi ke generasi. Tulisan ini kemudian akan mencoba untuk mengungkap sebagian dari itu melalui pendekatan Poskolonial dengan cara menggali pengalaman bangsa Yahudi sebagai bangsa jajahan yang digambarkan dengan "Tanduk Kecil" dalam Daniel 8. Kitab Daniel yang menyimpan pengalaman Daniel sebagai jajahan bangsa Babel tapi juga sebenarnya ditujukan untuk pembaca Yahudi yang sementara dalam penjajahan itu kemudian didialogkan dengan pengalaman bangsa Indonesia yang pernah menjadi bangsa jajahan Jepang. Dialog kedua konteks ini akan memperlihatkan bahwa memori penjajahan bisa diartikan sebagai memori penderitaan.

kata kunci : Perjanjian Lama, Kitab Daniel, Poskolonial, Antiochus IV Epiphanes, Kolonialisme Jepang, Yahudi, Indonesia.
\end{abstract}




\section{A. PENDAhuluan}

Almarhum kakek saya, Alfred Andasia Pemberiang, dahulu sering bercerita bagaimana ia dan keluarganya hidup di masa Penjajahan Jepang. Sewaktu mengalami penjajahan itu, ia sudah memasuki masa pemuda sehingga masih teringat banyak tentang masa tersebut. Ia juga pada waktu bercerita kepada saya, masih ingat beberapa kata Bahasa Jepang karena memang ia menerima didikan dari kurikulum orang Jepang. Tapi yang paling ia ingat adalah bagaimana orang Jepang begitu kejam terhadap orang-orang yang ia kenal. Beberapa orang dari keluarga kami ada yang dihukum mati, ada yang disiksa, ada pula yang hingga kini hilang entah kemana.

Perhatian dari perspektif poskolonial adalah hal-hal yang seperti ini. Ingataningatan mengenai penjajahan yang pernah dialami tentu berdampak bagaimana kita sebagai orang Indonesia menjalani kehidupan. Seperti yang disampaikan oleh Rey Chow sebagaimana dikutip Sugirtharajah mengartikan postcolonial dengan bertolak dari ungkapan post di depannya yakni berjalan melampaui, setelah, dan catatan tentang waktu yang tidak terjadi secara linear tetapi konstan, dicirikan oleh peristiwaperistiwa yang mungkin secara teknis sudah berakhir tetapi hanya bisa sepenuhnya dimengerti dengan perhatian terhadap penghancuran yang sudah ditinggalkan di belakang. ${ }^{1}$ Penghancuran itulah yang dialami oleh kakek saya dan masih saya warisi sampai sekarang. Menariknya, penghancuran ini bukan sekedar diwariskan begitu saja tapi diwariskan dalam bentuk simbol. Dengan demikian, simbol yang membentuk kebudayaan menjadi juga bentuk perlawanan. Karena di dalam simbol-simbol itu terkandung memori-memori penting yang turut membentuk kebudayaan dan kehidupan di masa kini. Inilah yang coba diperlihatkan melalui artikel ini.

Kitab Daniel yang dalam bentuknya sekarang kita miliki sebenarnya juga ditulis pertama-tama untuk orang-orang Yahudi yang hidup di bawah penjajahan Yunani dalam hal ini di bawah pemerintahan Antiochus IV Epiphanes. ${ }^{2}$ Dalam pasal 8, si pencerita dalam Kitab Daniel kemudian mempergunakan gambaran "Tanduk Kecil" yang menurut banyak ahli adalah Antiochus IV Epiphanes tersebut. Gambaran yang dijelaskan dalam bagian ini sebenarnya juga adalah gambaran bagaimana si pencerita yang mungkin mewakili orang-orang Yehuda di masa itu melihat dan memahami penjajah mereka yaitu Antiochus itu. 
Dalam tulisan ini, saya memperhatikan konteks Politik dari teks Daniel 8 secara khusus gambaran "Tanduk kecil" yang adalah Antiochus IV Ephipanes sebagai penjajah bangsa Yahudi serta mendialogkannya dengan gambaran "Dai Nippon" yang adalah Jepang sebagai penjajah Bangsa Indonesia. Kedua gambaran itu menjadi jalan bagi saya untuk memperlihatkan bagaimana simbol-simbol yang dipakai sesungguhnya menjadi alat pewaris memori penderitaan yang dialami oleh bangsa jajahan, bahkan bisa dikatakan itu menjadi alat untuk membentuk kebudayaannya sendiri. Untuk itu, pertama-tama saya memberikan sebuah penjelasan singkat mengenai Kitab Daniel karena ini adalah sebuah karya Tafsir dari salah satu pasalnya. Kemudian saya menjelaskan mengenai gambaran "Tanduk Kecil” sebagai sebuah gambaran atas penjajah mereka setelah terlebih dahulu secara umum menjelaskan keseluruhan pasal 8 yang menjadi pasal pokok dari tulisan ini. Setelah itu berdasarkan data-data yang ada, saya menjelaskan mengenai gambaran Jepang di mata orang Indonesia sebagai jajahan mereka. Lalu yang terakhir, saya akan mendialogkan kedua gambaran mengenai Antiochus dan Jepang tadi.

\section{Tentang Perspektif Poskolonial}

Seperti dikatakan oleh Leela Gandhi, poskolonialisme sesungguhnya adalah medan pertarungan berbagai disiplin ilmu dan teori. ${ }^{3}$ Karena memang analisis poskolonial hadir sebagai sebuah kepedulian tapi yang menggunakan berbagai perangkat demi mencapai tujuannya. Ia hadir sebagai upaya untuk mengkaji bagaimana penjajahan pernah dan terus terjadi hingga kini. Yang menarik menurut Gandhi adalah bagaimana poskolonialisme sebagai sebuah analisis, menggunakan penggabungan antara teori-teori yang bertentangan seperti Marxisme dan postrukturalisme. Walaupun demikian, wacana poskolonialisme pertama kali diperkenalkan oleh orang-orang di dunia sastra.

R. S. Sugirtharajah juga ketika menjelaskan perbedaan kritik poskolonial dalam studi Alkitab dengan kritik-kritik yang ada sebelumnya mengatakan, bahwa sementara kritik-kritik tersebut berfokus pada sejarah, teologi dan dunia keagamaan dari teks sedangkan kritik poskolonial justru lebih memperhatikan unsur politik, budaya dan ekonomi dimana teks itu muncul, walaupun memang kedua-duanya memperhatikan konteks darimana teks tersebut muncul. ${ }^{4}$ Homi Bhabha sebagai seorang tokoh analisis poskolonial sebenarnya hadir sebagai sebuah kritik bagi para pendahulunya. Selama 
ini atas rintisan dari Edward Said dan Frantz Fanon, analisis poskolonial sudah berkembang pesat dan menjadi kaca mata analisis yang menggiurkan untuk dipakai dalam mengkaji persoalan penindasan yang terjadi. Tapi Bhabha di sini memperlihatkan, bahwa para pendahulunya terlalu dikotomis dalam memandang hubungan antara penjajah dan yang terjajah. ${ }^{5}$ Bagi Bhabha, hubungan antara pihakpihak itu selalu ambigu bahwa hibrid. Perlawanan yang dilakukan oleh yang terjajah terhadap si penjajah tidak selalu konfrontatif.. Hubungan penjajah dan yang terjajah selalu ada dalam ambiguitas dan hibriditas.

Bhabha memahami poskolonialitas dalam kerangka "beyond". Kerangka poskolonialitas selalu bersoal pada bagaimana seseorang menempatkan kebudayaan tertentu. Bahkan hal itu bukan cuma soal penempatan bahkan sampai pada situasi dimana kebudayaan itu terbentuk kembali. Dengan demikian situasi "beyond" itu mensyaratkan kemampuan intersubjektif dan internasionalitas yang membuat kategori-kategori dikotomis tidak mencukupi lagi. Inilah kenapa kategori perlawanan yang dikotomis sudah tidak mencukupi lagi untuk menjelaskan bagaimana hubungan Penjajah dan yang terjajah. Dalam menjelaskan bagaimana hubungan teori dan dunia politik, Bhabha menyebutkan bahwa hibriditas adalah sebuah keniscayaan. Kondisi ini disebabkan upaya untuk melihat realitas bukan semata-mata dari singularitas tapi juga dari bagaimana posisi ras, lokasi institusi dan lingkup geopolitik, dll. yang menentukan identitas di dunia modern. Yang penting sekarang menurut Bhabha adalah bagaimana berpikir dengan melampaui narasi-narasi originalitas dan asal muasal suatu subjek, tapi lebih dari pada itu yaitu berfokus pada bagaimana proses pembentukan budaya-budaya yang berbeda. Maka bagi Bhabha, yang paling penting adalah bagaimana pembentukan kebudayaan. ${ }^{6}$

\section{Kitab Daniel}

Kitab ini memiliki judul Daniel karena cerita dan penglihatan-penglihatan di dalamnya berkisar pada pribadi yang bernama Daniel. Setengah bagian pertama dari Kitab ini (Pas. 1-6) mengandung cerita tentang sekitar pengalaman Daniel dan temantemannya di hadapan Raja yang menunjuk Daniel sebagai orang ketiga. Setengah bagian lagi mengandung penglihatan-penglihatan oleh Daniel yang ditulis dalam sudut pandang orang pertama. Menurut W. Sibley Towner, Kitab Daniel mengandung 
tulisan-tulisan dari beberapa penulis yang bekerja di waktu-waktu yang berbeda. Ini menyangkut perbedaan mendasar tentang dua bagian buku ini yaitu bahwa kitab ini ditulis dalam dua bahasa (Dan. 2:4b-7:28 ditulis dalam Bahasa Aram, sisanya dalam Bahasa Ibrani). Menurutnya paling luas diterima adalah pandangan H. L. Ginsberg, bahwa keseluruhan Kitab (kecuali Doa dalam 9:4b-20) ditulis dalam lingua franca pada masa itu, Bahasa Aram dan bahwa 1:1-2:4a ditambah Pasal 8:12 kemudian diterjemahkan ke dalam Bahasa Ibrani mungkin agar bagian Kitab itu bisa lebih diterima oleh komunitas yang mensucikan Bahasa Ibrani. ${ }^{7}$

Kitab ini kemudian biasanya dibagi dalam dua bagian, Daniel 1-6 biasanya disebut dengan Daniel A, sedangkan Daniel 7-8 disebut sebagai Daniel B. Dari segi isi, seluruh Kitab Daniel dapat dikatakan termasuk ke dalam sastra Apokaliptik, tetapi Daniel B masih lebih apokaliptik daripada Daniel A. Bahkan mungkin dapat dikatakan Daniel B merupakan sastra apokaliptik par excellence, oleh karena berulang kali menyebutkan mengenai akhir sejarah, sedangkan Daniel A hanya menyebutkan mengenai akhir dari zaman tertentu dalam sejarah. ${ }^{8}$

Kitab ini banyak dipersoalkan karena data-data sejarah yang berada dalam isinya. Pertama, bagian awal yang menunjuk ke penyerangan Nebukadnezar ke Yerusalem pada tahun ketiga dari Pemerintahan Yoyakim (609-598 SM), yaitu pada tahun 606 SM (ay. 1) yang kalau menurut Yeremia 25:1 saja, Nebukadnezar naik tahta nanti pada tahun keempat dari Pemerintahan Yoyakim pada tahun 605 (SM), belum lagi dengan data-data yang lain. Kedua, disebutkan dalam Kitab ini, Belsazar menjadi penerus dan anak dari Nebukadnezar (5:1). Tapi sebenarnya ia adalah anak dari Nabonidus bukan Nebukadnezar. Menurut catatan sejarah, Nebukadnezar digantikan oleh anaknya Amel-Marduk, yang memerintah sekitar dua tahun (562-560 SM). Ketiga, kitab ini bercerita tentang Darius dari Mede, anak dari Ahasyweros (9:1), tapi dalam rekaman sejarah tidak pernah disebut seorang Mede yang bernama Darius. Data-data ini memang sulit untuk didamaikan dengan sejarah, tapi seperti dikatakan oleh C. L. Seow bahwa nilai dari Kitab Daniel sebagai Kitab Suci bukanlah tergantung pada ketepatan sejarah tapi pada kekuatan dari pesan teologisnya. Otoritas dari kitab ini sebagai sebuah kitab suci terletak pada kekuatannya untuk menginspirasi dan membentuk komunitas iman. ${ }^{9}$ Seperti dikatakan tadi, bahwa Kitab Daniel dalam bentuknya sekarang tanpa diragukan lagi disusun selama masa pemerintahan dari Antiochus Epiphanes.Walaupun ia dikirim ke Roma pada tahun 189 SM, karena 
kekalahan ayahnya oleh orang-orang Roma, Antiochus kemudian naik jadi Raja pada 175 SM melalui serangkaian kebetulan.

\section{Si Tanduk Kecil}

Pada bagian ini saya lebih berfokus pada Tanduk Kecil tentang apa yang dilakukan dan artinya sehingga apa yang di dapat dari situ nantinya akan didialogkan dengan perlakuan orang Jepang terhadap orang Indonesia. Tanduk Kecil ini muncul di dalam konteks penglihatan yang sedang dialami oleh Daniel di pinggir Sungai Ulai. Di sana Daniel melihat ada dua binatang yang terlebih dahulu muncul yaitu domba jantan dan kambing jantan. Domba tersebut dikalahkan oleh si kambing yang kemudian memunculkan empat tanduk. Nah, tanduk kecil itu muncul dari salah satu tanduk dari keempat tadi. Berdasarkan penafsiran dari malaikat Gabriel, Domba Jantan itu melambangkan Kerajaan Media-Persia (ay. 20) sedangkan Domba Jantan berarti Kerajaan Yunani (ay.21). Menurut E. G. Singgih, gambaran binatang-binatang di dalam Pasal 7-8 berfungsi untuk menimbulkan secara dramatis kesadaran akan situasi genting yang sedang dihadapi oleh Daniel dan teman-temannya di kerajaan Babel dan Persia, seperti yang kita lihat dalam konteks cerita dari Daniel 7-12. Ia lalu membanding gambaran-gambaran dalam kedua pasal itu, kalau di pasal 7 binatangbinatang Khaos yang muncul digambarkan tanpa merujuk secara eksplisit pada konteks historis. Penjelasannya pun menghindar dari memberi petunjuk yang jelas. Namun, pada pasal 8 gambaran domba jantan dan kambing jantan secara eksplisit dikaitkan dengan kerajaan Media-Persia dan Yunani (mulai dari Aleksander Agung sampai kepada keturunan Seleukus). ${ }^{10}$

Para penafsir kebanyakan setuju bahwa Tanduk kecil itu melambangkan Antiochus IV Epiphanes. ${ }^{11}$ Gambaran tersebut sebenarnya sudah pernah muncul pada pasal 7, di mana itu muncul sebagai gambaran atas Antiochus Epiphanes juga. Sekarang dikatakan bahwa si tanduk kecil itu muncul dari salah satu tanduk dari keempat yang muncul dari Domba Jantan setelah tanduknya yang perkasa itu patah, yang memilki kemungkinan bahwa ia muncul dari wilayah Seleukus. Mengapa kemudian ia disebut kecil tidaklah jelas. Mungkin kata sifat itu berarti bahwa siapa yang dimaksud dengan Tanduk Kecil itu ingin dibedakan dengan "tanduk yang besar" (ay. 8), Alexander yang hebat. Antiochus memang kalau dibanding dengan si Perintis 
Kekaisaran Yunani, memang tidak ada apa-apanya, ia hanya Tirani Lokal. Tetapi ia tentu punya peranan penting dalam sejarah orang Yahudi sehingga ia kemudian disebut bertambah besar bahkan sampai ke sorga (ay. 10) ${ }^{12}$. Pada awalnya dikatakan dalam ayat 9 kalau Tanduk itu akan menjadi lebih besar sampai ke arah Selatan, Timur, dan Tanah Permai. Ini melambangkan kegiatan-kegiatan militer dari Antiochus, dimakan ia bergerak ke arah Timur Siria (I Mak. 3), upayanya melawan Mesir (I Mak. 1), dan pelecehan yang dilakukannya di Yerusalem. ${ }^{13}$. John Collins melihat dari sudut pandang lain mengenai penglihatan ini. Ia menyimpulkan, bahwa sebenarnya tujuan dari tindakan-tindakan Tanduk Kecil itu adalah Bait Yerusalem, dan itu bisa dilihat dari ayat-ayat sesudahnya yang sebagian besar menyangkut penyerangan di Bait tersebut ${ }^{14}$. Sehingga bisa dilihat bahwa penggambaran Tanduk Kecil ini memang berfokus pada penjajah bangsa Yahudi di masa itu.

Apa yang dilakukan oleh Antiochus kepada bangsa jajahannya bisa dilihat dalam ayat-ayat selanjutnya yang memang ingin memberi penegasan tentang hal tersebut terlebih khusus dalam ayat 11-12 tentang kesombongan Tanduk Kecil itu. Dalam ayat 10-12 digambarkan bagaimana Tanduk Kecil itu bisa sampai mengganggu ketentraman Sorga. Sebagaimana diketahui bahwa salah satu ciri khas dari tulisan apokaliptik adalah kesatuan antara sorga dan bumi. Maksudnya, apa yang terjadi di sorga seperti dalam tulisan apokaliptik sebenarnya menggambarkan apa yang terjadi di bumi. Ini dimulai menurut Seow, sebenarnya sejak ayat 9 dimana dikatakan Tanduk Kecil itu menjadi sangat besar sampai ke Tanah Permai. Yerusalem yang disebut Tanah Permai sebenarnya lebih menunjuk kepada Gunung Sion yang merupakan Sanctuary Allah. Jadi, Antiochus berani-beraninya menantang Allah di tempatNya yang kudus ${ }^{15}$. Yang seperti itu juga dilanjutkan dalam ayat 11 dimana Ia digambarkan membesarkan diri terhadap Panglima bala tentara yang merujuk kepada Allah. Ayat 12 kurang jelas Menurut Norman Porteous, tapi berdasarkan ayat 13 kita dapat menyimpulkan, bahwa yang dimaksud dalam ayat itu adalah suatu kebaktian diadakan secara fasik menggantikan korban sehari-hari adalah sesuatu yang dilakukan untuk mengotori atau melecehkan Altar ${ }^{16}$. Ini mempertegas apa yang dilakukan oleh Antiochus terhadap unsur-unsur keagamaan orang-orang Yahudi. Dalam bagian ayat 12 selanjutnya dikatakan kebenaran dihempakan oleh si Tanduk Kecil itu sampai ke bumi, yang kelihatannya ia menggambarkan kejatuhan dari kebenaran yang diyakini 
oleh Penulis dan Pembaca Kitab Daniel. Collins pun berkata demikian bahwa kebenaran yang dimaksud di sini bukanlah kebenaran yang abstrak tapi menunjuk kepada Hukum dan Adat Istiadat Yahudi. ${ }^{17}$ Jadi, kita melihat disini, bahwa Antiochus digambarkan menantang Allah dengan merusak unsur-unsur peribadatan, adat istiadat serta hukum-hukum bangsa Yahudi. Penggambaran Antiochus tidak sampai di situ saja karena pada ayat-ayat selanjutnya dalam pasal ini, Malaikat Gabriel sendiri juga mengartikan Tanduk Kecil untuk Daniel.

Gabriel mengatakan setelah akhir kerajaan dari empat kerajaan hasil pecahan Tanduk Besar, maka akan muncul Raja dengan muka garang dan pandai menipu. Ungkapan muka garang juga muncul dalam Ul. 28:50 untuk menggambarkan negara yang akan dikirim oleh Tuhan karena Israel telah melanggar perjanjian. Tapi menurut Collins, dengan itu bukan berarti kita bisa mengatakan bahwa Antiochus bisa dilihat sebagai sebuah kutuk yang diturunkan kepada Bangsa Yahudi karena melanggar perjanjian. Cukuplah menurut dia, untuk kita mengatakan bahwa ungkapan "muka garang" disini berarti bahwa Antiochus merupakan Raja yang dikirim untuk melawan Israel. Sedangkan ungkapan "pandai menipu" itu sebenarnya secara literer berarti "seseorang yang mengerti teka-teki". Itu pada awalnya bermakna baik, tapi untuk Antiochus dipakai makna negatif yang berarti "seseorang yang mampu bersepakat dengan dua belah pihak", jadi Antiochus digambarkan sebagai seseorang yang melakukan kesepakatan dengan dua pihak yang bermusuhan untuk akhirnya dia sendiri yang diuntungkan. ${ }^{18}$ Tanduk kecil tersebut kemudian dalam ayat selanjutnya dikatakan bahwa kekuatannya akan menjadi hebat, tetapi tidak sekuat dahulu dan ia akan mendatangkan kebinasaan yang mengerikan, dan apa yang dilakukannya akan berhasil; orang-orang berkuasa akan dibinasakannya, juga orang kudus (ay. 24). Bagi Towner, fokus utama dari tindakan dari si Tanduk Kecil itu adalah pelecehannya terhadap ibadah dan altar Bait Allah, sehingga tindakan-tindakan dalam ayat 24 harus dilihat dalam sudut itu ${ }^{19}$. Seowpun senada juga berpikir demikian, bahwa kita bisa mengartikan ayat 24 dengan merujuk kepada penyerangan dan pengrusakan kepada perkakas Bait Allah. ${ }^{20}$ Sedangkan "Orang-orang yang berkuasa” yang dibinasakan oleh Antiochus menurut Collins bisa juga diartikan Pemangku Takhta Siria ${ }^{21}$. Jadi selain motif keagamaan seperti dikatakan tadi, disini juga ada yang lain yaitu unsur politik dimana proses perebutan kekuasaan terjadi didalamnya. 
Ayat 25 mencatat bahwa Tanduk Kecil itu kemudian oleh karena akalnya melakukan penipuan yang berhasil. Ini merujuk kepada tindakan-tindakan Antiochus agar dapat merebut tahta. Lebih lanjut, si Tanduk Kecil itu kemudian katanya akan "membesarkan dirinya dalam hatinya", yang kalau dilihat dari ayat 11 ini merujuk kepada kesombongan Antiochus yang semakin besar. Gambaran mengenai dirinya berlanjut dengan "tak disangka-sangka banyak orang akan dibinasakannya", yang secara umum biasanya diartikan sebagai penyerangan tiba-tiba di Yerusalem seperti dilaporkan dalam 1 Mak. 1:29-30. Sekali lagi muncul sikap Antiochus yang berani menantang Allah dalam "ia akan bangkit melawan Raja segala raja", ${ }^{22}$ Jadi, sampai di sini kita sudah melihat bagaimana penulis Kitab Daniel menggambarkan Tanduk Kecil alias Antiochus sebagai raja yang melecehkan ibadah dan Altar Bait Suci, memperebutkan Kekuasaan dengan kerajaan lain, dan membunuh orang-orang Yahudi.

\section{Si Dai Nippon}

Dalam bagian ini, saya akan menguraikan beberapa pengalaman mengenai Penjajahan Jepang di Indonesia yang nanti akan saya dialogkan dengan Tanduk Kecil. Saya menggunakan istilah Dai Nippon yang merupakan istilah dari propaganda kekaisaran Jepang pada zaman perang dunia pertama dan kedua. Dai Nippon merupakan istilah yang sangat populer di masa Perang Asia Timur Raya untuk mengganti nama dari kekaisaran Jepang. ${ }^{23}$ Pada mulanya orang Indonesia umumnya menyambut kedatangan Jepang dengan perasaan gembira. Jepang dianggap sebagai pembebas dari penjajahan Belanda. Serdadu-serdadu Jepang itu menimbulkan rasa kagum penduduk ketika mereka memasuki kota-kota tanpa mendapat perlawanan dari pasukan Belanda. Faktor utama yang menimbulkan simpati rakyat terhadap Jepang tentu saja kebencian mereka terhadap Belanda, baik akibat penderitaan yang lansung mereka rasakan, maupun akibat perasaan kebangsaan. Kata "banzai" terucap berulang-ulang dan keras dari mulut-mulut penduduk yang terbius ketika Tentara Jepang datang yang berarti "selamat datang". Di samping itu, terdapat pula faktorfaktor lain seperti kepercayaan akan kebenaran ramalan Joyoboyo, propaganda Jepang melalui siaran Radio, dan daya tarik barang-barang "made in Japan" yang murah harganya sehingga terjangkau oleh daya beli masyarakat. ${ }^{24}$ Setelah berjalan satu dua bulan rezim baru Jepang tiba-tiba mengubah kata banzai (hidup Jepang) dengan 
bakero, mengganti bendera Merah Putih dengan bendera Hinomaru, dan mengganti lagu Indonesia Raya dengan Kimigayo. Rezim baru ternyata malah makin mendorong rakyat Indonesia ke jurang penderitaan yang melebihi penderitaan yang dialami di bawah pejajahan Belanda. Pelecehan terhadap adat istiadat dan agama mayoritas penduduk, pemerasan ekonomi, serta pengerahan tenaga secara paksa untuk kepentingan perang, terjadi di masa itu.

Ini menarik sebab semua itu memicu protes pertama secara halus oleh Hatta kepada penguasa pemerintahan militer di Jawa dengan nasihat agar orang-orang Jepang menghentikan kebiasaan mereka menampar kepala orang Indonesia. Karena bagi orang Indonesia kepala adalah bagian tubuh yang dianggap suci, dengan melakukan hal itu sebenarnya orang Indonesia akan merasa terhina. Selain itu, ada juga protes terhadap kewajiban melaksanakan seikeirei (membungkukkan badan ke arah matahari terbit sebagai penghormatan kepada Kaisar Jepang) yang bertentangan dengan ajaran Islam. Bagi penganut Islam, hanya Tuhan yang wajib disembah. Orang boleh saja menyembah orang lain yang ada di depannya, tetapi bukan menyembah orang yang tidak kelihatan. ${ }^{25}$

Ternyata selain pengalaman dari Kakek saya, masih ada juga pengalamanpengalaman yang lain. Tentara Peta misalnya merasakan benci yang semakin besar kepada Jepang ketika lama-kelamaan mereka mulai merasakan betapa rendahnya martabat mereka dalam pandangan orang-orang Jepang. Mereka harus memberi hormat lebih dahulu kepada serdadu Jepang yang pangkatnya lebih rendah. Romusa sebagai bentuk kerja rodi di zaman Jepang adalah pengalaman lain yang tak kalah pahitnya. Orang-orang yang melaksanakan Romusa dipaksa melakukan pekerjaan berat dari pagi sampai sore, hampir tanpa istirahat. Namun, makanan dan kesehatan mereka tidak diperhatikan sehingga banyak jatuh sakit dan meninggal dunia. Bahkan untuk menggantikan romusa laki-laki yang meninggal dunia, Jepang mengerahkan romusa wanita. Merekapun mengalami penderitaan yang tidak kurang hebatnya dengan penderitaan romusa laki-laki.

Pengalaman yang terjadi di Sumatera juga sama saja tapi tidak separah di Jawa, harga-harga makanan dan keperluan rumah tangga terasa bedanya dengan masa Belanda. Hampir semua bahan-bahan pokok disana harus diprioritaskan dahulu untuk Jepang atas nama kepentingan perang Asia Timur Raya. Sementara itu, rakyat yang 
mayoritas petani dianjurkan untuk tetap rajin bekerja di sawah dan ladang mereka. Akan tetapi sebagian besar hasilnya harus diserahkan untuk keperluan perang Jepang. Di Minang kebanyakan orang yang sudah terbiasa makan nasi tiga kali sehari atau sekurang-kurangnya dua kali sehari, maka di masa pendudukan Jepang banyak yang tidak pernah melihat nasi. Kalaupun ada, seringkali beras bercampur jagung dan sering sudah berjamur. Selain makanan, bahan kain pun amat sulit ditemukan. Akibatnya, banyak orang yang menggunakan bahan kain kasur atau kain gorden pintunya diubah menjadi baju atau celana. Sumatera barat khususnya, kesulitan untuk mendapatkan bahan pakaian, bahkan kain usang sekalipun, menyebabkan banyak orang terpaksa memakai bahan karung goni atu kulit kayu tarok (sejenis pohon tanaman tua yang tebal serat kulitnya) HAMKA, seorang sastrawan Minang yang terkenal, setelah menyaksikan sendiri dan menangkap fenomena kekejaman Jepang dan menuangkannya ke dalam bait-bait pantunnya berikut ini ${ }^{26}$ :

\section{Beras yang putih untuk Jepang \\ Di kita jagung campur ubi \\ Banyak bicara kena lampang ${ }^{27}$ \\ Kalau melawan dihukum mati}

Di Kalimantan Barat sering terjadi perlakuan kasar serdadu Jepang terhadap penduduk, seperti menjatuhkan hukuman jemur sampai pingsan terhadap orang yang hanya melakukan kesalahan kecil. Kekejaman mereka semakin meningkat setelah sekutu sejak permulaan tahun 1943 melancarkan serangan udara terhadap kedudukan mereka. Orang-orang yang dicurigai oleh Jepang kemudian ditangkap bahkan ada yang dihukum pancung depan umum. ${ }^{28}$

\section{Dialog Tanduk Kecil dan Dai Nippon}

Uraian di atas kiranya sudah memberi bahan yang cukup bagi kita untuk mulai mendialogkan kedua gambaran Tanduk Kecil alias Antiochus IV Epiphanes dan Dai Nippon alias Jepang. Banyak kesamaan yang terdapat pada bagaimana cara kedua Penjajah ini memperlakukan bangsa jajahannya. Sebagaimana yang telah diuraikan tadi mengenai Tanduk Kecil bahwa fokus dari tindakan-tindakan binatang itu terutama merujuk kepada tindakan-tindakan Antiochus yang merusak unsur-unsur keagamaan bangsa Yahudi. Perusakan itu seperti mengganggu Ibadah di Bait Allah dan pelecehan 
terhadap perkakas-perkakas di dalamnya yang kemudian juga menjadi pelecehan terhadap altar. Jika dilihat dari uraian mengenai sikap Jepang terhadap bangsa Indonesia terutama yang ada hubungannya dengan unsur keagamaan ternyata ada juga hal seperti itu. Sikap-sikap Jepang terhadap bangsa Indonesia terutama pada saat telah beberapa lama menjajah Indonesia seperti dikatakan tadi banyak melecehkan agamaagama yang dianut oleh rakyat. Saya tidak mendapat sikap Gereja terhadap hal ini tapi yang paling bersoal tentang hal ini terutama adalah Islam. Kewajiban untuk melakukan Seikeirei yaitu penghormatan ke arah Timur setiap hari dipandang tidak cocok dengan Syariah karena bagi mereka menyembah kepada sesuatu yang tidak kelihatan terlarang. Hal yang berhubungan dengan itu adalah pengrusakan adat istiadat Yahudi yang diungkapkan dengan "kebenaran dihempaskan ke Bumi (ay. 12)" sebenarnya juga dialami oleh bangsa Indonesia. Yang mungkin agak berbeda adalah bagaimana orang Jepang merendahkan orang Indonesia seperti yang dikritik oleh Mohammad Hatta tentang bagaimana orang Jepang sering memukul kepala orang Indonesia. Ini adalah sikap merendahkan karena bagi orang Indonesia, kepala adalah bagian tubuh yang suci.

Mengenai kekejaman yang dilakukan oleh si Tanduk Kecil dan Dai Nippon bisa dilihat dari bagaimana Antiochus menyerang Yerusalem secara tiba-tiba banyak orang dibunuh, ini diungkap dengan "tanpa disangka-sangka banyak orang akan dibinasakannya (ay. 25)". Sama dengan yang diceritakan oleh Kakek saya bagaimana keluarga kami dibunuh dan orang-orang Indonesia yang lain dihukum mati berupa pancung oleh orang Jepang. Belum lagi kalau dihitung dengan pembantaian tentara Jepang terhadap Para Pemberontak yang sudah merasa muak dengan sikap Jepang. Kalau Tanduk Kecil digambarkan sebagai yang akan membinasakan orang berkuasa (ay. 24) sebagai merujuk kepada Antiochus yang berusaha berkuasa atas Siria sama dengan Jepang yang berhasil membombardir Pearl Harbour milik Amerika Serikat lalu berhasil mengusir Belanda yang menjajah Indonesia ratusan tahun. Perbedaan antara kedua gambaran ini adalah bagaimana orang Jepang memperlakukan orang Indonesia sehingga membawa kesengsaraan yang begitu besar. Yang ada dalam gambaran Tanduk Kecil, hanya diberikan penekanan pada pelecehan di bidang agama, ada juga politik tapi terutama soal agama sehingga persoalan-persoalan kemanusiaan belum terlalu nampak di sini. Penderitaan bangsa Yahudi yang 
dinampakkan khususnya dalam bagian ini adalah bagaimana mereka merasa terhina ketika Antiochus berulang kali melecehkan identitas keagamaan mereka. Penderitaanpenderitaan yang lain misalnya seperti yang dialami oleh bangsa Indonesia berupa kerja paksa Romusa, penindasan ekonomi yang mengundang kelaparan tidak terlihat.

Istilah Dai Nippon dan Simbol Tanduk Kecil walaupun dalam beberapa hal memiliki kesamaan terkait pengalaman penderitaan yang dialami sebagai bangsa jajahan juga punya perbedaan yang mendasar. Simbol Tanduk Kecil boleh juga dikatakan sebagai sebuah simbol sindiran bahwa Antiochus IV Ephiphanes ini sesungguhnya adalah sosok kecil dan tidak terlalu berpengaruh dalam sejarah dunia. Meskipun kecil tapi memiliki dampak yang besar bagi orang Yahudi terbukti dari penderitaan yang dialami. Simbol Tanduk Kecil adalah bentukan dari orang-orang yang terjajah. Istilah Dai Nippon berbeda karena pada awalnya adalah bentukan dari para penjajah. Bahkan simbol tersebut merupakan alat propaganda dari Jepang. Dengan demikian, walaupun memiliki kesamaan dalam hal penderitaan yang dialami, tapi kedua simbol ini mempunyai asal muasal yang berbeda. Hal penting untuk dilihat juga bahwa ada beberapa perbedaan dalam hal pengaruh kedua simbol ini dalam pembentukan kebudayaan dari kaum terjajah. Bagi Yahudi, simbol ini menjadi salah satu unsur penting karena termasuk dalam Sastra Apokaliptik. Jenis tulisan ini menjadi unsur penting karena termasuk dalam salah satu korpus tulisan suci Hebrew Bible. Berarti dalam hal ini, simbol penjajah ini sudah menjadi satu unsur pembentukan kebudayaan dari orang Yahudi. Simbol Dai Nippon sendiri bukan menjadi satu simbol yang terus diulang sampai sekarang. Simbol ini hanya menjadi kenangan bagi orang-orang yang sudah pernah merasakan penjajahan Jepang.

Simbol Tanduk Kecil dalam hal ini membenarkan pandangan poskolonial bahwa hubungan antara penjajah dan yang terjajah tidak selamanya selalu konfrontatif. Tapi memori itu menjadi perlakuan para penjajah itu dipergunakan sedemikian rupa orangorang yang pernah terjajah untuk dirumuskan dalam simbol dan menjadi unsur penting dalam kebudayaannya. Dengan demikian, ini juga menjadi perwujudan dari mimicry atau peniruan yang terjadi dari yang terjajah terhadap penjajah. Yang terjajah dalam hal ini Yahudi menggunakan memorinya tentang penjajah untuk dipergunakan dalam kepentingan kebudayaannya sendiri seperti yang nampak dalam sastra apokaliptik. Dengan demikian kelihatan bahwa memori penjajah itu bukan sekedar untuk dikenang tapi juga membentuk jati diri dari yang terjajah. 


\section{B. PENUTUP}

Penelusuran analitik mengenai memori penjajahan yang dialami oleh orang Yahudi melalui simbol Tanduk Kecil dan pengalaman sejarah Indonesia menuntun pada bagaimana memori kedua konteks ini memiliki kesamaan dalam beberapa hal. Kesan umumnya ialah memori penjajahan bisa selalu diartikan sebagai memori penderitaan dan perlawanan. Walaupun begitu terdapat beberapa hal berbeda juga yang perlu ditekankan terutama pada bagaimana simbol itu diwarisi untuk kemudian menjadi unsur penting yang turut membentuk identitas kaum yang terjajah itu.

\section{Endnotes:}

${ }^{1}$ Rey Chow, Between Colonizers in R. S. Sugirtharajah, Asian Biblical Hermeneutics and Postcolonialism, (New York: Orbis Books, 1998), ix.

${ }^{2}$ C. L. Seow, Daniel: Westminster Bible Company (Louisville: Westminster John Knox Press, 2003), 23.

${ }^{3}$ Leela Gandhi, Teori Poskolonial: Upaya Meruntuhkan Hegemoni Barat (Yogyakarta : Kalam, 2014), 4.

${ }^{4}$ R. S. Sugirtharajah, Exploring Postcolonial Criticism: History, Method, Practice (West Sussex: Blackwell Publishing, Ltd., 2012), 2.

5 Odniel H. Gultom, MENGHADAPI TANTANGAN MONSTER KHAOS: Memahami Apokalitisipsisme Teks Daniel Pasal 7:12 Menggunakan Teori Poskolonial Homi Bhabha dan Relevansinya Dalam Konteks Indonesia (Yogyakarta : Tesis Universitas Kristen Duta Wacana, 2016), 9.

${ }^{6}$ Homi K. Bhabha, The Location of Culture (London: Routledge, 1994), 2.

${ }^{7}$ W. Sibley Towner, Daniel: Interpretation (Georgia: John Knox Press, 1984), 5.

${ }^{8}$ E. G. Singgih, "Dari "Godzilla" ke "Bandot": Fungsi Penglihatan mengenai Binatang-binatang di Daniel 7-8 dalam Bagian kedua Kitab Daniel," in Apokaliptik : Kumpulan Karangan Simposium Ikatan Sarjana Biblika Indonesia 2006, ed. Y. M. Seto Marsunu (Jakarta: Lembaga Alkitab Indonesia, 2007), 20.

${ }^{9}$ Seow, Daniel , 5-6.

${ }^{10}$ Singgih, Dari "Godzilla" $k$ e "Bandot", 41.

${ }^{11}$ John J. Collins, Daniel: A Commentary on the Book of Daniel (Minneapolis: Fortress Press, 1993) 331. ; Seow, Daniel, 121. ; Norman W. Porteous, Daniel: A Commentary (Philadelphia : Westminster Press, 1965) 124. ; W. Sibley Towner, Daniel: Interpretation, 120.

${ }^{12}$ Seow, Daniel, 121.

${ }^{13}$ Porteous, Daniel, 120.

${ }^{14}$ Collins, Daniel, 331.

${ }^{15}$ Seow, Daniel, 122.

${ }^{16}$ Porteous, Daniel, 125-126.

${ }^{17}$ Collins, Daniel, 335.

${ }^{18}$ Collins, Daniel, 339-40.

${ }^{19}$ Towner, Daniel, 123.

${ }^{20}$ Seow, Daniel, 131.

${ }^{21}$ Collins, Daniel, 341.

${ }_{22}^{22}$ Collins, Daniel, 341.

23 "Arti kata Dai Nippon", Blog Definisi Kata, accessed Desember 19, 2014, http://defenisikata.blogspot.com/2014/05/defenisi-dan-pengertian-dai-nippon.html,

${ }^{24}$ Amrin Imran et al., Indonesia dalam Arus Sejarah: Perang dan Revolusi (Jakarta: Ichtiar Baru van Hoeve dan Kementerian Pendidikan dan Kebudayaan Republik Indonesia, 2012) 21. 
${ }^{25}$ Imran et al., Indonesia dalam Arus Sejarah, 26-7.

${ }^{26}$ Imran et al., Indonesia dalam Arus Sejarah, 30.

${ }^{27}$ Lampang dalam bahasa Minang berarti tempeleng.

${ }^{28}$ Imran et al., Indonesia dalam Arus Sejarah, 32.

\section{DAFTAR PUSTAKA}

Bhabha, Homi K., The Location of Culture. London: Routledge, 1994.

Chow, Rey. Between Colonizers. in R. S. Sugirtharajah. Asian Biblical Hermeneutics and Postcolonialism. New York: Orbis Books, 1998.

Collins, John J., Daniel: A Commentary on the Book of Daniel. Minneapolis: Fortress Press, 1993.

Gandhi, Leela. Teori Poskolonial: Upaya Meruntuhkan Hegemoni Barat. Yogyakarta: Kalam, 2014.

Gultom, Odniel H., MENGHADAPI TANTANGAN MONSTER KHAOS: Memahami Apokalitisipsisme Teks Daniel Pasal 7:12 Menggunakan Teori Poskolonial Homi Bhabha dan Relevansinya Dalam Konteks Indonesia. Yogyakarta: Tesis Universitas Kristen Duta Wacana, 2016.

Imran, Amrin dkk., Indonesia dalam Arus Sejarah: Perang dan Revolusi. Jakarta: Ichtiar Baru van Hoeve dan Kementerian Pendidikan dan Kebudayaan Republik Indonesia, 2012.

Porteous, Norman W., Daniel: A Commentary. Philadelphia: Westminster Press, 1965.

Seow, C. L., Daniel: Westminster Bible Company. Louisville: Westminster John Knox Press, 2003.

Sibley, Towner W., Daniel: Interpretation. Georgia: John Knox Press, 1984.

Singgih, E. G., "Dari “Godzilla” ke "Bandot”: Fungsi Penglihatan mengenai Binatang-binatan di Daniel 7-8 dalam Bagian kedua Kitab Daniel." In Apokaliptik: Kumpulan Karangan Simposium Ikatan Sarjana Biblika Indonesia 2006, edited by Y. M. Seto Marsunu,. Jakarta: Lembaga Alkitab Indonesia, 2007.

Sugirtharajah, R. S., Exploring Postcolonial Criticism: History, Method, Practice. West Sussex: Blackwell Publishing, Ltd., 2012. 
"KETIKA MEMORI PENDERITAAN DIPERJUMPAKAN"

Sebuah Kajian Dialogis Kitab Daniel dan Sejarah Penjajahan Jepang di Indonesia dalam Perspektif Poskolonial

\section{Website Content}

Blog Definisi Kata ."arti kata Dai Nippon”. accessed Desember 19, 2014. http://defenisikata.blogspot.com/2014/05/defenisi-dan-pengertian-dainippon.html. 